\title{
Construction sites as shared workplaces - An occupational safety and health profile based on workplace inspection reports
}

Päivi Kekkonen, Arto Reiman, Seppo Väyrynen, Hanna-Kaisa Rajala

\begin{abstract}
A shared workplace, according to Finnish legislation, is a workplace in which one employer exercises the main authority while additional employers or self-employed workers operate simultaneously or successively in such a way that their work may affect the safety or health of other employees. This study aimed to form a holistic view of the occupational safety and health (OSH) challenges facing shared workplaces within the construction industry. The material consist-ed of randomised OSH inspection reports $(\mathrm{N}=79)$ from the Regional State Ad-ministrative Agency. Reports were analysed to gain information about the ob-served deficiencies. In the analysis, the reports were categorised based on the ho-listic work system model (ISO 6385, 2016). The analysis carried out in this study resulted in the recognition of common challenges at shared workplaces within the construction industry. Using this method, an individual observation profile for each industry branch can be formulated. Such profiles can be used in the planning of industry-specific inspection checklists for the supervision of OSH as well as in developing the OSH management at shared workplaces.
\end{abstract}

\section{Introduction}

A shared workplace is defined in Finnish legislation as a workplace in which one employer exercises the main authority while additional employers or self-employed workers operate simultaneously or successively in such a way that the work may affect the safety or health of other employees (Occupational Safety and Health Act 738/2002). The European Union (EU) directives on safety and health at work address a situation similar to that of a shared workplace, but they do not use a specific term for it, and they present less detail in the OSH Frame-work directive (Directive 89/391/EEC). Both the EU and Finnish legislation require that employers and self-employed workers at such workplaces ensure in adequate cooperation that their activities do not endanger employees' safety and health.

Shared workplaces occur in several industries but are most common in the construction, manufacturing and transportation and storage sectors. In the con-struction industry, almost all workplaces can be considered shared workplaces due to the fact that, at large construction sites, there are always employees of several different employers working on their specific areas of expertise (Häk-kinen \& Niemelä, 2015). In process and manufacturing industries, it is also very common that certain tasks, such as those related to maintenance, are carried out by contractors and their employees. Within the transportation and storage sector, shared workplaces often occur in the hubs of transportation routes, such as ports, airports and terminals and storages of ground transport (Turunen et al., 2015; Teperi, 2012; Reiman et al., 2015).

Despite the widespread occurrence of shared workplaces and increased out-sourcing of services and other tasks, which has become more and more common in many industries over the last few decades, the concept of a shared workplace is not very well known internationally, and research on the safety of shared workplaces is sparse (Rantanen et al., 2007; Nenonen, 2012). However, the chal-lenges related to safety management in situations in which cooperation and col-laboration among several employers and their employees are needed are similar in all industrialised countries (Rantanen et al., 2007). The challenges at shared workplaces often include service provider selection, safety management resource availability, hazard identification, communication, working culture, and employ-ee competence and training (Nenonen, 2012). Special needs related to shared workplaces in process industry companies' sites was a main 
contributor to the development of the Health, Safety, Environment, Quality Assessment Procedure (HSEQ AP), which is now widely applied in Finland (Väyrynen et al., 2012).

The work system model, which can be used to examine work and its elements, consists, in its basic form, of the following elements: the person or employee, his or her work task, the tools and technologies he or she uses to accomplish the task, the work environment and the organisation in which the work takes place (Smith \& Sainfort, 1989; Carayon \& Smith, 2000; Carayon, 2009). Depending on the input into the work system and the interplay of its elements, the work that is carried out in various processes leads to positive and/or negative outcomes. Ex-amples of positive outcomes include the productivity, health and wellbeing of the employees, while negative outcomes include stress, accidents, discomfort, absence from work and loss of time. Employees can be seen as important assets to an organisation, meaning their safety and health is essential to the perfor-mance of the whole organisation.

In this study, occupational safety and health (OSH) inspection reports were analysed to gain a holistic view of the OSH situation at shared workplaces within the construction industry. The challenges, special characteristics, situations and phenomena related to $\mathrm{OSH}$, viewed from the standpoints of different actors with-in the shared workplace, were the targets of interest in this study. The work sys-tem was used as a framework to compartmentalise the observations under analy-sis. The aim was to answer the following research questions:

1. What kind of OSH challenges exist at shared workplaces within the construc-tion industry?

2. What special characteristics, situations and phenomena exist at shared work-places within the construction industry?

\section{Study Design and Methods}

The materials analysed within this study were OSH inspection reports from the Regional State Administrative Agency of Finland. These inspections were carried out from 2012 to 2016. The analysed OSH inspection reports $(\mathrm{N}=79)$ were chosen randomly, but selection was done in such a way that all the inspections were targeted at workplaces in the construction industry and each inspec-tion report included at least one observed deficiency that led to a written advice or improvement notice by the agency. The cases were regarded as construction industry cases if the inspection took place at a construction site, even if the employer who was targeted in the inspection represented another branch of industry. This decision was made because the branch of the worksite being inspected was considered a main contributor to the possible hazards and deficiencies observed during the inspection.

Regional State Administrative Agencies' OSH inspections concentrate on safety risks, the management of overload and the minimum conditions of em-ployment, according to the supervision guidelines issued by the Ministry of So-cial Affairs and Health. The inspections also aim to help workplaces develop their OSH functions and work conditions. The situation at a workplace is ob-served on the basis of both discussion and documents, as well a visit to the work-place. In cases where the inspector observes matters that are contrary to OSH legislation, he or she issues written advice and improvement notices that are rec-orded in the inspection report.

In this study, observations within OSH inspection reports that led to written advice or improvement notices were analysed according to different thematic categories. The categories were formed in a larger analysis spanning 200 inspec-tion reports from various branches of industries, which resulted in 61 separate observation categories. An open coding approach was used to form themes aris-ing from the material 
(Flick, 2009). The categories were further divided accord-ing to the elements of the work system model, namely, organisation, employee, task, tools and technology, and work environment.

The categorisation was carried out by one researcher (PK), and the final set of categories was decided upon by the researcher and the expert from the Regional State Administrative Agency (H-KR). NVivo 11 Pro software, which was de-signed for analysing qualitative data, was used in the analysis. Each of the observations could belong to more than one category, and one inspection report could have more than one observation that belonged to a certain category. On the basis of this analysis, it was possible to recognise the categories on which the observa-tions at shared workplaces within the construction industry were focused.

\section{Results}

The analysis carried out on the OSH inspection reports aimed to answer the following research questions: "What kind of OSH challenges exist at shared workplaces within the construction industry?" and "What special characteristics, situations and phenomena exist at shared workplaces within the construction industry?" The results are presented in the following sections.

\section{Challenges at Shared Workplaces within the Construction Industry}

The observation categories that contain the most observations can be regarded as the main challenges experienced at shared workplaces within the construction industry. These are presented as a percentage of the total number of observations in Table 1. Four categories (i.e., deficiencies in planning, use of personal protec-tive equipment, fall hazard and access ways) could be clearly separated from the rest of the categories based on their prominence in the analysed material.

Table 1 Categories with most observations, presented as a percentage of the to-tal number of observations.

\begin{tabular}{ll}
\hline Observation category & $\%$ \\
\hline Deficiencies in planning & 12.0 \\
\hline Use of personal protective equipment & 11.1 \\
\hline Fall hazard & 10.5 \\
\hline Access ways & 9.4 \\
\hline
\end{tabular}

\section{The Observation Profile}

The observation profile that was based on the OSH inspection reports about construction worksites is presented in Figure 1. The profile presents the percent-age rates of all the observations in each category. The observation categories contained anywhere from 0 to 55 observations from the workplace inspection re-ports. For clarity, the observation categories are divided under the elements of the work system (i.e., organisation, employee, task, tools and technology, and work environment). Due to the large number of categories under the organisation element, these categories are further divided under the themes of human re-sources and documentation, safety management, occupational health and safety, occupational health service, and general practices.

The observation profile offers visual insight, both into the categories in which there are a lot of observations and into the categories in which there are none or only a small proportion of observations. To use the information provided by the gaps in the observation profile, background information is needed about the orig-inal checklists used in the workplace inspections that formed this material. How-ever, 
observation profiles, such as the one presented in Figure 1, can be used to develop checklists that target the special challenges of the industry branch in question (in this case, the construction industry).

\section{Discussion}

Looking at the results on categories related to organisation, a clear peak in de-ficiencies in planning can be seen. This area of safety in the construction indus-try has previously been identified as a challenge and a common factor contrib-uting to accidents (Häkkinen \& Niemelä, 2015; Rantanen et al., 2007; LindKohvakka, 2015). Observations related to access ways and fall hazards were also strongly present in the material. These are also common factors contributing to accidents in the construction industry (Häkkinen \& Niemelä, 2015).

The material used in this study-namely the workplace inspection reports-contains observations that have been detected as matters contrary to Finnish OSH legislation. Thus, the view represented in these results is based on the minimum level set by the legislation, and possible challenges and good practices that could be identified at similar worksites using other methods are not necessarily present in these results. The inspection reports were written by individual OSH supervi-sors, causing some variance in the level of detail in the reports; this variance may also be reflected in the analysis carried out by the researcher.

The material is also comprised solely of reports of workplace inspections tar-geted at shared workplaces. In the case of the construction industry, however, the situation is different than it is in many other branches of industry, as almost all construction sites are shared workplaces in which there are employees of several employers working simultaneously or successively in such a way that their work may affect other employees' safety or health. This said, the results can be seen as comparable to the results of earlier research related to $\mathrm{OSH}$ in construction worksites. 


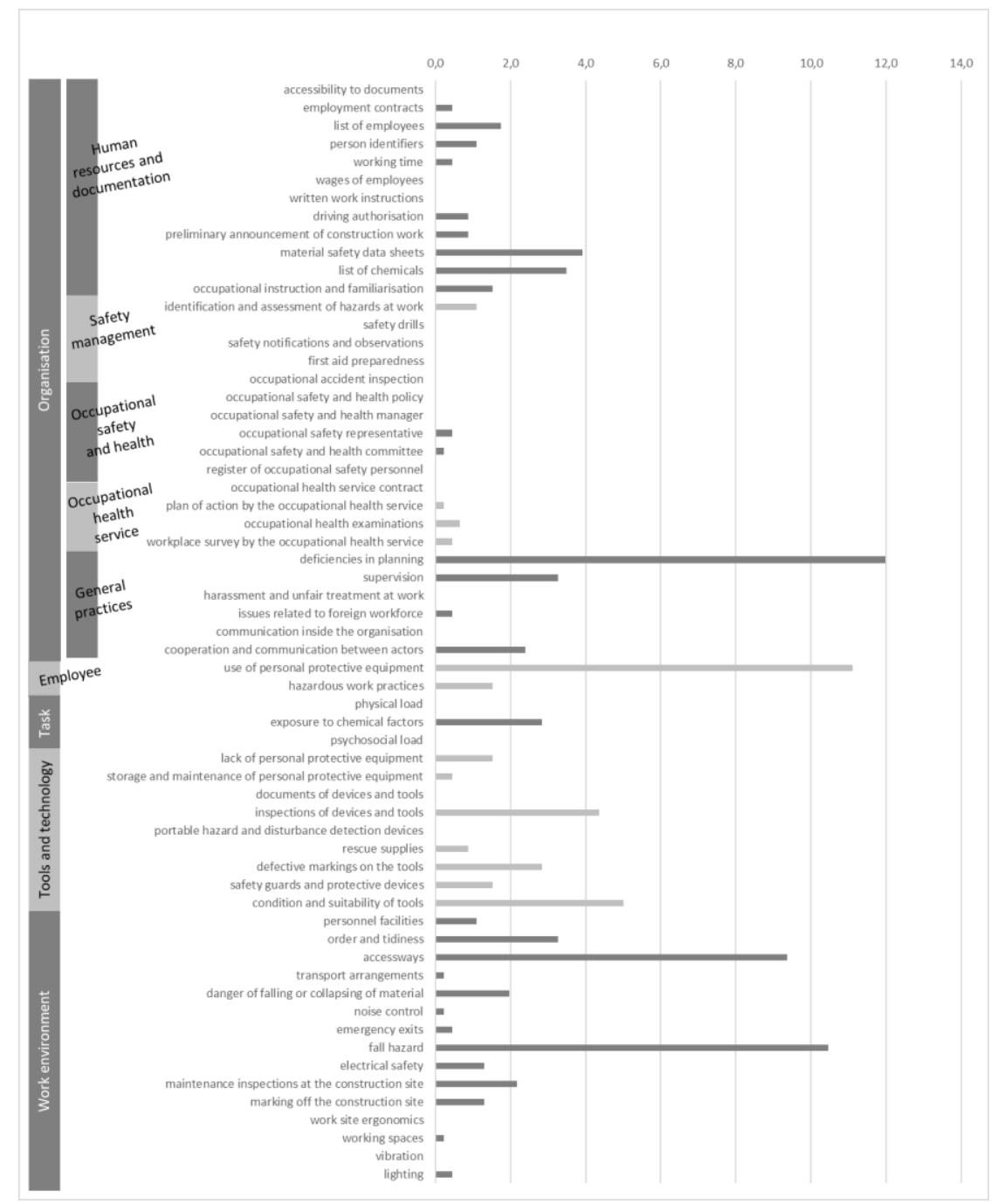

Figure 1 Observation profile presenting the percentage rates of observations in each category. For clarity, the categories are divided under the elements of the work system, with further classifications of various themes under the organisation element.

\section{Conclusions}

This study aimed to form a holistic view of the OSH challenges at shared workplaces within the construction industry. The concept of a shared workplace is not very well known or widespread internationally, although the situation of having several employers' employees working at the same worksite is identified in the EU legislation. Deeper, human-centred insight into the OSH challenges at shared workplaces could offer ways in which to tackle OSH issues in today's complex organisational environment, where shared workplaces and situations similar to these have become more and more widespread due to, for example, to outsourcing and networking.

The method presented in this study offers a way to formulate an individual observation profile for each industry branch. Such profiles can be useful in the planning of industry-specific inspection checklists for the supervision of OSH. In addition to OSH authorities, this information could also be utilised by experts of industries in which shared workplaces occur. In the construction industry - and other industries as well identifying the special characteristics and challenges related to shared workplaces could also be beneficial to the companies them-selves as they develop their OSH management. 


\section{References}

Carayon, P., 2009. The balance theory and the work system model ... twenty years later. International Journal of Human-Computer Interaction, 25(5), 313-327. [Online] Available at:

https://doi.org/10.1080/10447310902864928

Carayon, P. \& Smith, M.J., 2000. Work organization and ergonomics. Applied Ergonomics, 31(6), 649-662.

Council of the European Communities, 1989. Council directive of 12 June 1989 on the introduction of measures to encourage improvements in the safety and health of workers at work (89/391/EEC). OJ L 183, 1-14. [Online] Available at: http://eur-lex.europa.eu/legal-content/EN/TXT/PDF/?uri=CELEX:01989L039120081211\&from $=$ EN

Flick, U., 2009. An Introduction to Qualitative Research. Edition 4. London: Sage Publications Ltd.

Häkkinen, K. \& Niemelä, V., 2015. "Accident sources and prevention in the construction industry - Some recent developments in Finland." In Väyrynen, S., Häkkinen, K., Niskanen, T. (Eds.) Integrated Occupational Safety and Health Management. Solutions and Industrial Cases. Switzerland: Springer International Publishing.

ISO 6385, 2016. Ergonomics principles in the design of work systems. Interna-tional Organization for Standardization.

Lind-Kohvakka, S., 2015. "Application of accident information to safety pro-motion - Case industrial maintenance." In Väyrynen, S., Häkkinen, K., Niskanen, T. (Eds.) Integrated Occupational Safety and Health Management. So-lutions and Industrial Cases. Switzerland: Springer International Publishing.

Nenonen, S., 2012. Implementation of safety management in outsourced ser-vices in the manufacturing industry. Tampere (Finland): Tampere University of Technology. Publication 1023.

Ministry of Social Affairs and Health, 2002. "Special situations of organising work." In Occupational Safety and Health Act, 738/2002. Unofficial translation. [Online] Available at:

http://www.finlex.fi/en/laki/kaannokset/2002/ en20020738.pdf

Rantanen, E., Mäkelä, T., Sauni, S., Lappalainen, J., \& Piispanen, P., 2007. Yhteisten työpaikkojen työturvallisuus. TOT-raporttien analyysi. (Occupational safety of shared workplaces. Analysis of TOT reports). Tampere (Finland): VTT.

Reiman, A., Väyrynen, S., \& Putkonen, A., 2015. "Truck drivers' work sys-tems in environments other than the cab - A macro ergonomics development ap-proach." In Väyrynen, S., Häkkinen, K., Niskanen, T. (Eds.) Integrated Occupa-tional Safety and Health Management. Solutions and Industrial Cases. Switzer-land: Springer International Publishing.

Smith, M.J. \& Sainfort, P.C., 1989. A balance theory of job design for stress reduction. International Journal of Industrial Ergonomics, 4(1), 67-79.

Teperi, A.-M., 2012. Improving the Mastery of Human Factors in Safety Criti-cal ATM Organisation. Faculty of Behavioural Sciences, University of Helsinki. Helsinki (Finland): Yliopistopaino Unigrafia.

Turunen, H., Väyrynen, S., \& Lehtinen, U., 2015. "Introducing a scenario of a Seaport's HSEQ framework: Review and a case in Northern Finland." In Väyrynen, S., Häkkinen, K., Niskanen, T. (Eds.) Integrated Occupational Safety and Health Management. Solutions and Industrial Cases. Switzerland: Springer International Publishing. 
Väyrynen, S., Koivupalo, M., \& Latva-Ranta, J., 2012. A 15-year development path of actions towards an integrated management system: Description, evalua-tion and safety effects within the process industry network in Finland. Interna-tional Journal of Strategic Engineering Asset Management, 1(1), 3-32. 